\title{
Microanalytical Characterization of REE Phases in a Glauconitic Sandstone
}

\author{
Jon Yang ${ }^{1 *}$, Circe Verba ${ }^{1}$, Scott Montross ${ }^{1}$, Jessica Moore $^{2}$, Ronald McDowell $^{2}$, Mark McKoy $^{3}$ \\ ${ }^{1 .}$ National Energy Technology Laboratory, US DOE, Albany, OR \\ 2.West Virginia Geological and Economic Survey, Morgantown, WV \\ ${ }^{3}$ National Energy Technology Laboratory, US DOE, Morgantown, WV \\ *corresponding author: Jonathan.Yang@netl.doe.gov
}

The rare earth elements (REEs) are the 14 naturally occurring elements of the lanthanide group as well as yttrium (Y) and scandium (Sc). These elements are critical components of numerous modern technologies including lasers, electronics, and magnets. Most traditional sources of REEs are phosphatic minerals such as monazite and bastnasite, which require energy- and capital- intensive processes to extract and concentrate the REEs as salable products. With the current dynamics of the REE market and the intense demand for these critical elements, keen interest has been focused on identifying alternative sources of the REEs.

The glauconitic sandstones of the Bob's Ridge formation in West Virginia may in fact be one of these promising alternative resources. The Bob's Ridge sandstone is a member of the Huntersville Chert interval deposited during the Middle Devonian and consists of interbedded layers of Tioga Ash, Huntersville Chert, and the glauconitic sandstones of the Bob's Ridge formation. Exploratory studies have identified a mean total concentration of $\sim 900 \mathrm{ppm}$ REE with $37 \mathrm{ppm}$ and $300 \mathrm{ppm}$ of Sc and Y, respectively [1]. By comparison, the average concentration of REEs in the upper continental crust is $\sim 150$ ppm with average concentrations of $14 \mathrm{ppm}$ and $21 \mathrm{ppm}$ for Sc and Y [2]. Our focus in this study was to investigate the elevated concentrations of REEs, Sc, and Y in the Bob's Ridge Formation through microanalytical techniques.

Polished samples were imaged using a field emission scanning electron microscope (FE-SEM, FEI Inspect F) equipped with an energy-dispersive X-ray spectrometer (EDS, Oxford Instruments). The SEM was operated at $20 \mathrm{kV}$ accelerating voltage with a beam current of $\sim 100 \mathrm{nA}$ and a beam aperture of 4 at a working distance of $\sim 10 \mathrm{~mm}$. All samples were scanned in an overlapping serpentine pattern across the entirety of the sample area. Quantitative EDS analysis on the REEs was calibrated against certified REE phosphate standards (REEP25-15 + FC, Astimex Standards Ltd.) and oxides (Standard block \#489, Geller Microanalytical Laboratory). X-ray diffraction (XRD) analyses were performed on powdered samples using a Rigaku XRD. Focused ion beam scanning electron microscopy (FIB-SEM) was used to collect image slices for a total volume of 30x30x10 $\mu \mathrm{m}$. PerGeos software was used for 3D segmentation as well as analysis of phase volumes and pore space distribution.

The Bob's Ridge Formation is characterized by a matrix of quartz, clay, and glauconitic grains. Large ( $>$ $100 \mu \mathrm{m}$ ) inclusions of a yellowish-brown iron phosphate mineral were observed under a light microscope. In addition to these large grain inclusions, iron phosphate minerals were observed as veins running through both quartz and glauconite grains (Fig. 1). This observation would suggest that the iron phosphate veins formed sometime after glauconization. Also present in the samples is an iron silicate phase which occurs as an infilling cement in the intergranular pore space (Fig. 1). Within the glauconite grains, SEM-EDS identified the presence of a REE-phosphate mineral, usually submicron to micron in size, interbedded in the fabric of the glauconite (Fig. 2). The association of REE-phosphates within glauconite suggests a co- 
genetic evolution of these two mineral phases or possibly a secondary replacement mineral through continued glauconization. The REEs are notably absent in the Fe-silicate/Fe-phosphate mineral inclusions, suggesting that the formation of these mineral phases were separate and independent [3].

\section{References:}

[1] R. McDowell, Geol. Soc. Am. (2012).

[2] R.L. Rudnick and S. Gao, Treatise on Geochemistry 3 (2003), p. 1-64.

[3] J.Y. acknowledges support from the NETL Research Participation Program, sponsored by the U.S. DOE and administered by the Oak Ridge Institute for Science and Education.
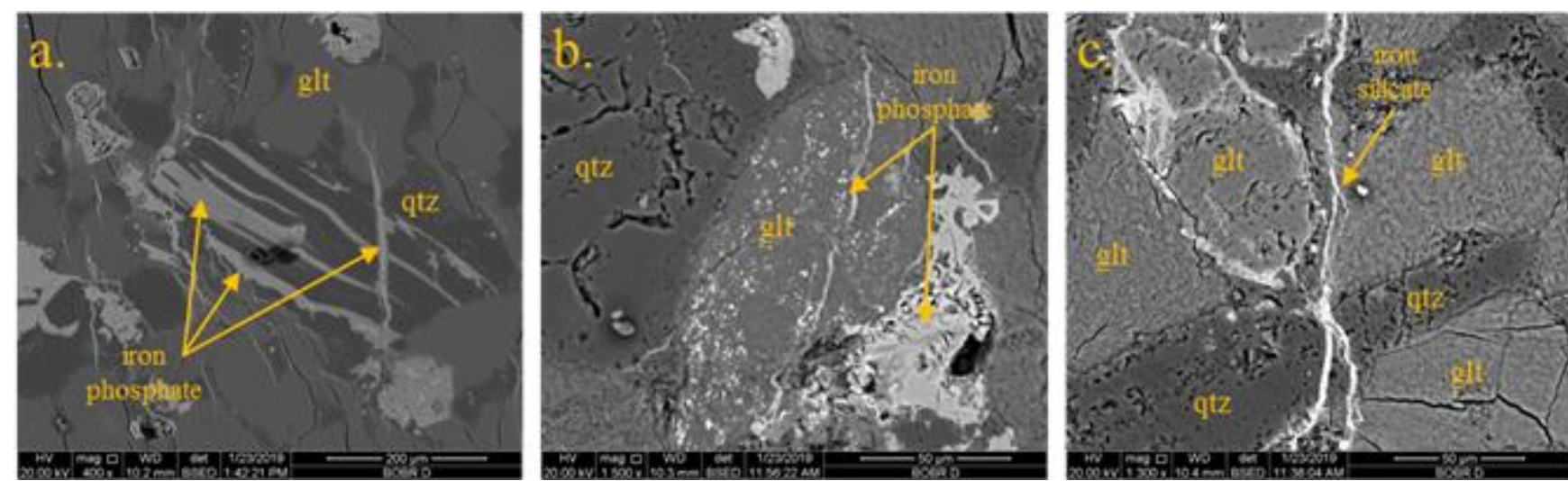

Figure 1. Back-scattered electron (BSE) images of Bob's Ridge Sandstone showing quartz (qtz), glauconite (glt), iron phosphate, and iron silicate phases. a. iron phosphate veins running through a quartz grain. b. iron phosphate vein and concretion running through a glauconite grain. c. iron silicate cements in the intergranular pore space.
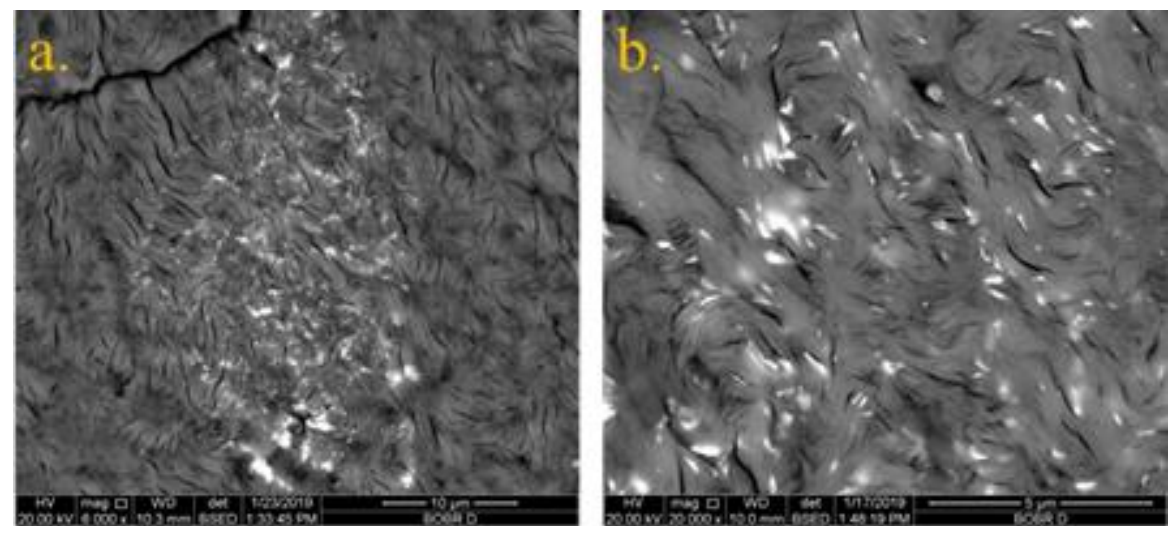

Figure 2. Back-scattered electron (BSE) images of REE-phosphate phases (bright spots) hosted within glauconite grains. a. 6,000x magnified view of REE-phosphate phases in glauconite. b. BSE image showing the size $(<1 \mu \mathrm{m})$ and location of the REE-phosphate phases within the glauconite. 